\title{
Traditional Medicine Utilization Experience among Persons Living With Mental Disorders within a Nigerian Community
}

\author{
Gbe Douye ${ }^{1}$, Adika Victor Obosinde ${ }^{2 *}$, Izibeloko Omi Jack-Ide \\ ${ }^{1}$ Graduate Student, Department of Community Nursing, Niger Delta University, Nigeria \\ ${ }^{2}$ Lecturer, Department of Medical-Surgical Nursing, Niger Delta University, Nigeria \\ ${ }^{3}$ Professor, Department of Mental Health Nursing, Niger Delta University, Nigeria
}

DOI: $10.36348 /$ sjnhc.2021.v04i01.005

| Received: 02.01.2021 | Accepted: 13.01.2021 | Published: 29.01.2021

*Corresponding author: Adika Victor Obosinde

\section{Abstract}

Globally, a mental disorder is identified as one main disorder that impends human existence consequently with an increasingly burdensome problem, causing victims many years lived with disability. Though the experience of mental disorder is universal, and the interpretation of the experience, notions of causation, treatment, and preferred source of care, varying from one culture to another. This study examines experiences of traditional medicine utilization among persons living with mental disorders within the community with the lens of phenomenological research design. It involved 13 participants and with the use of a structured interview guide as an instrument for data collection. Data were audio-recorded and thematically analyzed using the four phases of phenomenological explication. Thirteen participants comprised two patients recovering from mental illness, two herbalists, one faith healer, and eight family caregivers to patients. Participants were within the ages of 20-above 50years of age. Eight males and five females participated in the study. Most of the participants had an O-level certificate, were mostly farmers, were Christians, and spoke the local Ukawani language. Results from the study were under three main themes, firstly on the pattern of utilization which revealed that persons living with mental disorders in Obiaruko Community, Delta State reported the use of traditional medicine. Secondly on commonly used traditional medicine which includes herbs, prayers, and spiritual healing/cleanings, and thirdly, on factors influencing use which indicates that decision to use was based on the belief on the perceived effectiveness of traditional medicine. The main cause of mental disorders identified by participants was spiritual, evil spirit, and ancestral involvement. It is recommended that Federal and State Government guidelines and legislature be made for improved and applied utilization of traditional medicine and nurses should actively participate in improving mental health services particularly at a community level.

Keywords: Experiences, Persons Living with Mental Disorder, Traditional Medicine, Utilization.

Copyright (C) 2021 The Author(s): This is an open-access article distributed under the terms of the Creative Commons Attribution 4.0 International License (CC BY-NC 4.0) which permits unrestricted use, distribution, and reproduction in any medium for non-commercial use provided the original author and source are credited.

\section{BACKGROUND OF STUDY}

Mental disorder is identified globally as a disorder that threatens human existence and has resulted in an increasingly burdensome problem, causing many years lived with disability. It is estimated that $30 \%$ of the World's total population suffer from mental disabilities that have led to, social vulnerability, marginalization, and series of societal conflicts, including imprisonment, drug use, homelessness, and increased mortality rate [1]. Moreover, Chilale and colleagues attest to the fact that mental disorders are the number one non-communicable diseases contributing to an approximated $13 \%$ of global disease liability [2].

In 2016, it was also noted that mental disorders will result in an increased chance of death in the universal populace and may add up to $0.04-0.18$ of the disease condition in Africa by 2020 [3]. Despite the high rate of mental disorders, only a small percentage of people receive any form of modern treatment and most remain untreated. It is a documented fact that among $76 \%-85 \%$ of persons suffering from mental disorders, a majority do not receive any form of treatment [4]. It is also observed that in developing countries like Nigeria, dedicated health care system for mental disorders are highly insufficient, which have led people to consult different pathways for their mental health care. One of such pathways identified is the use of traditional medicine [4]. People around the globe have continued to depend on traditional medicine as a growing health care system due to its economic and custom values to them. It is however noted to be used by about $20-28 \%$ of the world's population in different forms [5]. 
African's have a long history of traditional medicine utilization with about $70 \%-95 \%$ of the general population using it. In some West African countries, traditional medicine utilization for treatment of conditions like malaria, hypertension, cancer, and even for antenatal patients has been highly documented [5]. The high rates of utilization of traditional medicine in cases of mental disorders have also been documented, for example, in Ghana and parts of Nigeria, people prefer traditional medicine for mental disorders [6].

In African cultures, for instance, mental disorders are thought to be the effect of a breach of taboos or customs, inimical familial spirits, demonical possessions, evil machination and intrusion of objects, evil eye, conflicts in social relations, magic, affliction by God or gods and those who hold such belief prefer traditional medicine as the best of treatment [7].

Different factors have however been identified to influence the choice of management of mental disorders with traditional medicine. Ikwuka et al., [3] noted beliefs system, values, a conception of mental health, idioms of distress, and social network as societal factors that influence traditional medicine utilization. The difference in the socio-cultural meaning of mental disorders, personal experience, cultural factors mainly characterized by stigma was also noted by [8]. Gender, marital status, age, educational level, income, deteriorating health status, and metabolic disorders perceived poor health status, safety, and affordability of treatment were also identified as factors to the utilization of traditional medicine [9].

Although global reviews play a valuable part in identifying key questions, there remains a gap in publications of traditional medicine utilization among persons living with mental disorders in Nigeria. The local inquiry remains an essential part of providing tangible proof about the existing realities and specific background factors. Thus, this study, therefore, seeks to examine experiences of traditional medicine utilization among persons living with a mental disorder in Obiaruko Community, Delta State.

History affirms the fact that mental disorders have constantly afflicted human society. With the general improvement of the health care system in the African continent, mental disorders still have a limited allocation for its services in the national health care budget as less than $2 \%$ is allocated to it and Nigeria is not an exception to this as a member of developing countries [7]. A high incidence of mental disorders is noted to be a consequence of the non-utilization of orthodox medicine [10].

As a result of inadequate modern amenities together with strong cultural practice, mental disorders have been credited to supernatural causes, ranging from spirit possession, evil eye, and not on the biomedical causes. This has led to persons living in the communities seeking care with the use of traditional medicine. Utilization of traditional medicine has always been a primary aspect of health-seeking behavior in Africa setting like Nigeria and it's highly considered by people of the communities as a valid source of treatment. The utilization of traditional medicine varies across the country especially among persons living with mental disorders. Beliefs play a vital role in the utilization of traditional medicine which influences help-seeking behavior greatly. Each region in Nigeria is influenced by varying factors that make them prefer traditional medicine over orthodox treatment for mental disorders. However, Cultural perception, the definitions of illness, cultural beliefs, and social support affect the health-seeking behaviors and utilization of various treatment methods.

Proper examination of the utilization of traditional medicine especially among persons living with mental disorders should be considered. Despite the popularity of traditional medicine and its use, most literature in Nigeria especially the South-South region of the country, where this study is conducted, shows that different studies have however been conducted [5] but there are few available research works in line with this study but not in the area of interest and no published work is known to the author (traditional medicine utilization among persons living with mental disorders in Obiaruko Community, Delta State) have been conducted. To this end, this study is focused on examining the experiences of traditional medicine utilization among persons living with mental disorders in Obiaruko Community, Delta State.

\section{OBJECTIVES}

This study has the following objectives:

- Determine the pattern of experiences of traditional medicine utilization among persons living with mental disorders in Obiaruko Community, Delta State.

- Identify the commonly used traditional medicine among persons living with mental disorders in Obiaruko Community, Delta State.

- Identify the factors influencing traditional medicine utilization among persons living with mental disorders in Obiaruko Community, Delta State.

\section{RESEARCH METHODOLOGY}

A qualitative phenomenological research design was adopted for this study because the researcher intends to describe the lived experiences of individuals about a phenomenon as described by participants on the utilization of traditional medicine among persons living with mental disorders in a Nigerian Community, in Delta State [11]. 
It has effectively been utilized in a related study [12] suggests a possible success in its use for the present study.

Obiaruku is situated on latitude $5^{\circ} 51^{\mathrm{ee}} \mathrm{N} 6^{\circ} 09^{\mathrm{ee}}$ $\mathrm{E}$, with a land coverage of 2,016 square kilometers, is the Headquarters/Capital of Ukwani Local Government Area (LGA) of Delta State, South-South, Nigeria. It is one of the major homelands of the Ukwuani speaking (Akashiada) people. The Okpala-Ukwu of Obiaruku is the oldest male in the town. Gerontocracy where the oldest man is installed the traditional rule is practiced by the people. The people are a mono linguistic group, the Ukwuani, an Igbo dialect of the Delta extract [13].

A total of 68,710 , with 33,090 males and 35,620 females was the population as of 2005 . The town has 16,205 households and a population density of 168. Obiaruku is mainly a multicultural town, with the two main migratory groups: Okuzu and Umuebu people, tracing their origin to Umuebu, older community south-west of Obiaruku. Other communities that later settled include the Umuedede, the Umusume people, and the Obi-Ugbe people. Over the years, migrants from neighboring Urhobo communities, far away Yoruba communities, Igbo communities, and nomadic Hausa/Fulani people have settled in the town too till date [13].

Up until recent times, Obiaruku has five major quarters and one smaller entity sub-quarter. This pattern was changed greatly over time with some quarters altering names and splitting up mainly for political reasons [13].

A significant proportion of the population retain elements of their traditional beliefs and practices, which sometimes guide their health-seeking behavior and the fact that this region has to be fairly untouched particularly with the issues of traditional medicine utilization among persons living with mental disorders.

The traditional healer and the patients were interviewed at the traditional healing center located at Umuedede quarters with one family care, three of the family cares were at their home in Ogbe-Obiaruku quarters while the others were from Okuzu and ObiUgbe quarters, respectively.

In this study, the population consisted of three sets of participants (persons recovering from a mental disorder, significant family care givers, and traditional healers) who were selected to participate in this study base on the selection criteria. However, persons living with mental disorders in the community were an estimated number of $15-20$ persons according to the estimate given by the community elder who is also a traditional healer.
For phenomenological studies, the sample size may range from three to ten participants and aim at data saturation [11] the researcher started with five persons and move on until data saturation is attained at thirteen participants in line with the sample size of related qualitative studies in this area of interest [14]. When there is sufficient information to duplicate the study, the capacity to acquire new information has been accomplished, and when additional coding is not possible [15].

Non-probability sampling is more often applied for qualitative study [16] to purposively select its participants. Hence, this was adopted for this present study.

To be included in this study the following inclusion criteria were considered: People recovering from a mental disorder can communicate and are oriented to place, time, and person. Significant family caregivers to people suffering from a mental disorder. Those who voluntarily agree to participate in the study. Must be traditional healers and Persons above 18years of age.

A semi-structured interview guide was used as the instrument for data collection. A semi-structured interview guide was used to cover the main topics of the research [17]. The instrument was developed in the English language by the researchers, based on an extensive review and synthesis of literature and personal experience.

Trustworthy in qualitative research is done through four criteria of Credibility, Transformability, Dependability, and Confirmability [18].

In this present study, the credibility of the instrument was ensured by focusing on the research objectives through the use of a structured interview guide, use of different participants with the same instrument (persons recovering from mental illness, family care givers, and traditional healers) and prolonged engagement with the participants. Transferability was achieved after several presentations of this research work. Confirmability implies how much others confirm the research finding. Overview of conflicting cases, exact explanation of details is used to improve the validity.

The reliability of the data collected indicates that the participants conveyed a personal expression of traditional medicine utilization among persons living with mental disorders in the local context and consistently. It was made a sound in that it measured and produces conclusions consistent with common sense.

The data were composed through in-depth interviews, to ensure minimal disturbance and confidentiality, each participant was individually 
interviewed at a convenient place. The spur of the study was described to each participant before the interview commenced and participants gave their consent for participation and for the interview to be audio recorded. Interviews were conducted in places convenient to the participants. Four at a traditional healing center and others at their private home. The duration of each interview ranged from $30 \mathrm{mins}$ to one hour. Interviews were audiotaped to advance data capturing and later transcribed to make sense of the narrative data. The interview was structured with fixed questions and follow up questions prompted by the discussion and questions guided by the focus of the study. Participants were probed further to elicit experiences of traditional medicine utilization in the treatment of mental disorders.

\section{Method of Data Analysis}

The data were audio-recorded, transcribed, and analyzed. Four phases of phenomenological explication were adopted [14]. These includes:

- Sense of the whole: Texts were repeatedly read to edict the content and to get the intent of the interviewee as an entity, before breaking it into units.

- Discrimination of natural meaning units (NMUs): Texts were broken into naturally occurring denotation that permitted stress-free organization and analysis of data. Available data were listed, edited, and overwhelming unmanageable data excluded.

- Transformation of natural meaning units into psychologically expressed themes: Themes were recognized and grouped into the psychological themes, namely conceptualization and traditional medicine utilization among persons living with disorders types of traditional medicine treatment utilized and cultural influence on traditional medicine utilization among persons living with mental disorders.
- Synthesis of emerging themes into a consistent psychological structure:

This was accomplished by sharing it into two phases; firstly, main themes were created, and secondly, a narrative of the phenomena under study was established by combing the psychological insights enclosed. Data obtained was finally conveyed in text form.

Ethical consideration was achieved through a letter of introduction that was sought from the faculty of the Nursing Research Ethics Committee. The ethical permit was also sought from the Ministry of Health to secure entrance into the communities and serve as legal backing for the study. Informed consent was also gained from each participant. The participants were reassured of confidentiality. The interview process was explained, participants were not in any way pressured to participate in the interview section.

It was also emphasized that partaking was voluntary, and they were free to pull out at any time of the section. Before the commencement of the interview section, copies of the participant information sheet (PIS) were made available to all the participants and signed assenting to their approval to be part of the study.

\section{DATA PRESENTATION AND ANALYSIS Data Analysis}

Demographically, participants interviewed in this study had an age range between 20-50years and included 2 patients, 2 traditional healers, and nine family caregivers. One male and one female patient, two male traditional healers, three female, and five male family caregivers. Four female and nine male, seven $\mathrm{O}$ level certificate holders, three school leaving certificate and tertiary certificate holders. Five were farmers, three were traders, two civil servants, and one applicant. Nine Christians and four traditionalists and ten Ukwani speaking people and three Urhobo speaking people.

Table-1: Demographic variables of participants

\begin{tabular}{|l|l|l|}
\hline Demographic data & Frequency (13) & Percentage (100\%) \\
\hline Age & & \\
20-29 years & 2 & 15.8 \\
30-39 years & 2 & 15.8 \\
40-49 years & 6 & 46.1 \\
50 and above & 3 & 23.1 \\
\hline Sex & & \\
Male & 8 & 61.5 \\
Female & 5 & 38.5 \\
\hline Marital state & & \\
Single & 4 & 30.8 \\
Married & 9 & 69.2 \\
\hline Level of education & & \\
School leaving certificate & 3 & 23.1 \\
O level & 7 & 23.1 \\
Tertiary & 3 & 53.8 \\
\hline
\end{tabular}




\begin{tabular}{|l|l|l|}
\hline Occupation & & \\
Farming & 5 & 38.5 \\
Trading & 3 & 23.1 \\
Civil servant & 2 & 15.8 \\
Applicant & 1 & 7.6 \\
Traditional healer & 2 & 15.8 \\
\hline Religion & & \\
Christian & 9 & 69.2 \\
Traditionalist & 4 & 30.7 \\
\hline Tribe & & \\
Ukwani & 10 & 76 \\
Others & 3 & 23 \\
\hline
\end{tabular}

The finding revealed that most families and persons with mental health disorders used mostly traditional/spiritual models of treatment as the first point of contact. It is seen as the main and only means of treatment when the issues of mental disorders arise as reported by some participants. The findings here have demonstrated that participants prefer traditional medicine because of its perceived potency.

The study revealed various types of traditional medicine utilized among families and persons living with mental health disorders to include the following such as herbalists, spiritual healers, and traditional/spiritual Consolers. The preference according to some of the participants depends on the degree of the illness. This study has brought to fore that herbal medicines used include crude plant materials such as leaves, flowers, fruits, seeds, stems, woods, roots, fresh juices, gums, mixed oils, essential oils, resins, dry powders of herbs. The herbalists used herbs for almost all types of mental disorders treatment. Many of the participants stated that the preference for taking the mentally ill patients to the herbalist for treatment is because of the speedy recovery after the application of herbs prepared by the herbalists for the mentally ill to bathe, cook, and rubbing it mixed with concoction on the body. The participants testified that herbs have minimal side effects and can be obtained free or in most cases affordable because they believe that the foundation of good health is in the roots. The findings from the study are on a mentally ill patient who was treated and cured when the hospital could not provide an answer to the illness and the cure came from the various roots and herbs from different plants most of which are in liquid form and also in powder form.

The study revealed that it was easier to extract the bullets from the head which was considered safer using herbs tied round the head than going for an operation in the hospital. The findings revealed that mad pregnant women who are violent are better handled by the Traditional Birth Attendants who are mostly women. They massage the women using herbal mixtures with kernel oil to calm the situation and ensure a safe and smooth delivery. This was a case of substance abuse, e.g., excessive smoking and alcohol drinking. The traditional healer administered herbs to the patient and flushed out the toxic substance in the body and made him have a repulsive feeling for substance abuse.

Participants believe that healers in this category look at all aspects of the individual, spiritual, emotional, mental, and physical as interrelated. Some of the participants noted that mental disorder is not an ordinary illness, but an act of wickedness inflicted on others by people with demonic powers such as witches and wizards, juju priests, ritualists, occultic grandmasters, etc. From the study, Christians consider mental disorders as those possessed by evil spirits, which are mostly treated by offering prayers and casting out the evil spirit from the patient.

Culture has become a well-entrenched factor that influences the choice of the people in the study areas on traditional medicine utilization among persons living with mental disorders. The participants believe that mental disorders emanate from the evil actions of victims or spells from family members or wickedness from evil people. They described the work of this group of healers requiring working with energy, the mind, and the spirit. They believe that spiritual healers possess the power to diagnose, treat patients by spiritual and divination.

In mental cases caused by sheer wickedness (witchcraft attacks), the process is the best suited because what led to the mental problem is not physical like a lifestyle rather it is spiritual manipulation from the coven and needed high power to neutralize the spell which the spiritual healers and pastors have been playing a complementing role to cure the patients. Giving useful, valuable advice and explanation have proven to reduce, take away guilt, worries, and other painful feelings, such as conflicts, loss of loved one, and another confusing situation. 
Table-2: Theme 1-Pattern of traditional medicine utilization among persons living with mental disorders

\begin{tabular}{|c|c|c|}
\hline Patients & Herbalist & Family caregivers \\
\hline $\begin{array}{l}\text { Patients acknowledged taken to } \\
\text { traditional healers as the first point of } \\
\text { contact }\end{array}$ & $\begin{array}{l}\text { Prefer traditional medicine because } \\
\text { of its perceived potency. }\end{array}$ & $\begin{array}{l}\text { The first point of contact. It is seen as the main } \\
\text { and only means of treatment }\end{array}$ \\
\hline $\begin{array}{l}\text { "Since l was taken to the traditional } \\
\text { Centre for treatment and when I started } \\
\text { the treatment l have been using the } \\
\text { traditional medicine day and night very } \\
\text { often (One year). l have seen the case of } \\
\text { many persons who have used this } \\
\text { traditional medicine and became well } \\
\text { again. Initially, the sickness started as an } \\
\text { ordinary fever or normal day to day } \\
\text { weakness of the body after which l was } \\
\text { taken to the central hospital for treatment } \\
\text { where it was later discovered l was } \\
\text { having a mental issue or problem" } \\
\text { \{Participants no.1\} "Since I started the treatment } \\
\text { (6months) have been using it hence very } \\
\text { often" (participants no 2) }\end{array}$ & $\begin{array}{l}\text { "The utilization of traditional } \\
\text { medicine to treat patients living } \\
\text { with mental disorders is very } \\
\text { potent and result-oriented" } \\
\text { \{Participants no.5\} } \\
\text { "I always use traditional } \\
\text { medicine for any form of treatment } \\
\text { because the foundation of good } \\
\text { health is in the roots irrespective of } \\
\text { the nature of illness or sickness, } \\
\text { but I prefer the traditional } \\
\text { medicine" (Participants no 4) }\end{array}$ & $\begin{array}{l}\text { "Frequently (1 year) base on cultural beliefs } \\
\text { and other known cases that have been } \\
\text { successfully treated and sometimes neglect I } \\
\text { resort to using it for my brother" (Participants } \\
\text { no 3) } \\
\text { "Occasionally, especially since we } \\
\text { considered the usefulness of traditional } \\
\text { medicine for mental disorders based on cultural } \\
\text { beliefs on the effectiveness of traditional } \\
\text { medicine" (Participants no } 6) \\
\text { "Very often since we left the hospital } \\
\text { using different kinds of roots and herbs" } \\
\text { (Participants no.7\} } \\
\text { "I prefer traditional medicine because its } \\
\text { treatment is faster compared to orthodox care" } \\
\text { (Participants no.8) } \\
\text { "Traditional medicine remains the } \\
\text { best form of treatment for mental disorders" } \\
\text { (Participants no 10) }\end{array}$ \\
\hline
\end{tabular}

Table-3: Themes 2- Commonly Used Forms of Traditional Medicine

\begin{tabular}{|c|c|c|}
\hline Patients & Traditional healers & amily caregivers \\
\hline They used herbs & $\begin{array}{l}\text { They used herbs and } \\
\text { incantations }\end{array}$ & Ierbs and prayers \\
\hline $\begin{array}{l}\text { "I inhaled burned herbs } \\
\text { for weeks and did not } \\
\text { sneeze for close to one } \\
\text { month which is an } \\
\text { indication that my case } \\
\text { was a severe one, but } \\
\text { the repeated application } \\
\text { of herbs brought a cure } \\
\text { for me". \{Participants } \\
\text { no.1\} } \\
\text { "This was a case of evil } \\
\text { spiritual attack; } \\
\text { dreamt and saw a bomb } \\
\text { coming to hit me and } \\
\text { someone in the dream } \\
\text { asked me to run and l } \\
\text { felt being pressed down } \\
\text { by a heavy stone and } \\
\text { woke up with a splitting } \\
\text { headache which was the } \\
\text { beginning of madness. } \\
\text { The spiritual healer } \\
\text { mixed the gun powder } \\
\text { with herbs and used it } \\
\text { to bathe me with the } \\
\text { instant result I became } \\
\text { calm immediately" } \\
\text { (Participants no.2) }\end{array}$ & $\begin{array}{l}\text { "In my local dialect, it is } \\
\text { called the 'Akoniuche" } \\
\text { meaning the powerful } \\
\text { power (the roots and } \\
\text { herbs)". (Participants no } \\
\text { 4) } \\
\text { "This is a spiritual case } \\
\text { and the people have } \\
\text { always relied on the } \\
\text { spiritual healers for a } \\
\text { solution and it has proven } \\
\text { to be the best form of } \\
\text { treatment for quick result. } \\
\text { The traditional method } \\
\text { (medicine) is amazingly } \\
\text { fast and quick in treatment } \\
\text { of persons living with } \\
\text { mental disorders" } \\
\text { \{Participants no.5\} }\end{array}$ & 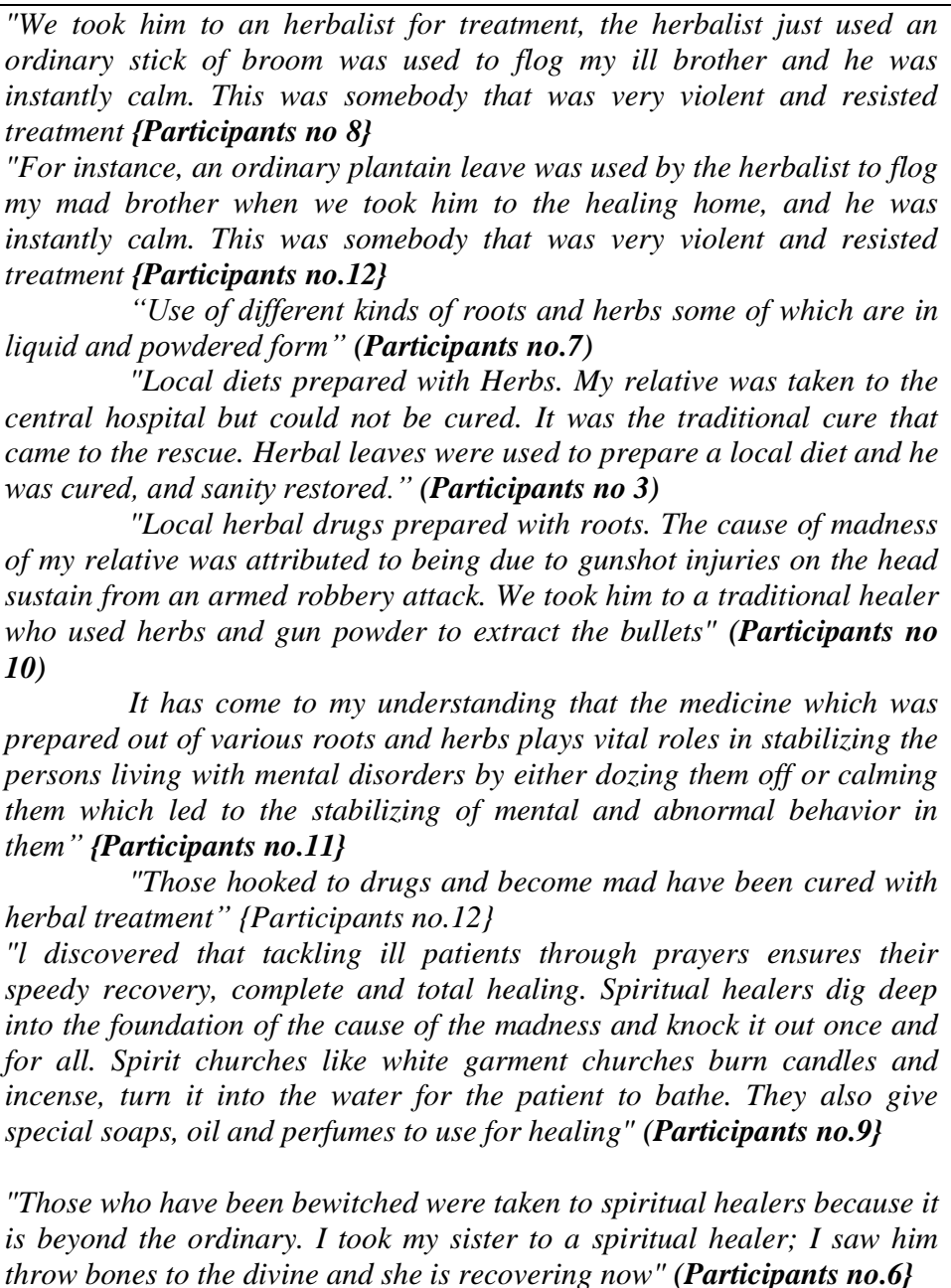 \\
\hline
\end{tabular}


Table-4: Theme 3- Influencing traditional medicine utilization among persons living with mental disorders

\begin{tabular}{|c|c|c|}
\hline Patients & Traditional healers & Family caregivers \\
\hline Spiritual origin & $\begin{array}{l}\text { Spiritual and requires spiritual } \\
\text { intervention }\end{array}$ & The source is not ordinary \\
\hline $\begin{array}{l}\text { "Sheer wickedness/spiritual } \\
\text { curses type of mental disorder } \\
\text { has become much more } \\
\text { common from the ancient days } \\
\text { to the modern-day. Take for } \\
\text { instance someone who sleeps } \\
\text { well and at night and woke up } \\
\text { with illness and starts } \\
\text { screaming and calling out at } \\
\text { people others cannot see } \\
\text { Ancestral reverence protects } \\
\text { family members and also heals } \\
\text { those with mental disorders. } \\
\text { Traditional consultation is the } \\
\text { way out" }\{\text { Participants no } 2\} \\
\text { "The healers often trace the } \\
\text { source of knowledge to } \\
\text { religious teachings because } \\
\text { spirits are believed to most } \\
\text { likely to enter people body } \\
\text { during odd hours or in the } \\
\text { farm, during the course of the } \\
\text { celebration of traditional } \\
\text { festivals, swimming in the river } \\
\text { and reading of occultic books } \\
\text { and other demonic practices } \\
\text { when the laws are violated. In } \\
\text { some cases, the healer will lead } \\
\text { the patient to sweep around a } \\
\text { circle with a prepared broom } \\
\text { which was used to sweep the } \\
\text { body of the patient from head to } \\
\text { toe with muttering of } \\
\text { incantations as a symbolic } \\
\text { spiritual cleansing" } \\
\text { \{Participants no.1\} }\end{array}$ & $\begin{array}{l}\text { "Some mad people are } \\
\text { suffering from ancestral } \\
\text { curses, that is evils of their } \\
\text { fore father's and need } \\
\text { spiritual cleansing" } \\
\text { \{Participants no 4\} } \\
\text { "My experiences as a healer, } \\
\text { there is a limit to which the } \\
\text { orthodox medicine can go in } \\
\text { terms of mental disorder } \\
\text { treatment. The issue of mental } \\
\text { disorder is a complex one and } \\
\text { as such must be treated } \\
\text { spiritually and anything } \\
\text { spiritual is not regarded as } \\
\text { important to medical issues. } \\
\text { Usually, mental disorders are } \\
\text { believed to be inflicted on } \\
\text { people who have committed } \\
\text { certain offenses beyond } \\
\text { forgiveness. Sometimes it is as } \\
\text { a result of witchcraft or } \\
\text { wickedness as the case may } \\
\text { be" (Participants no 5) }\end{array}$ & 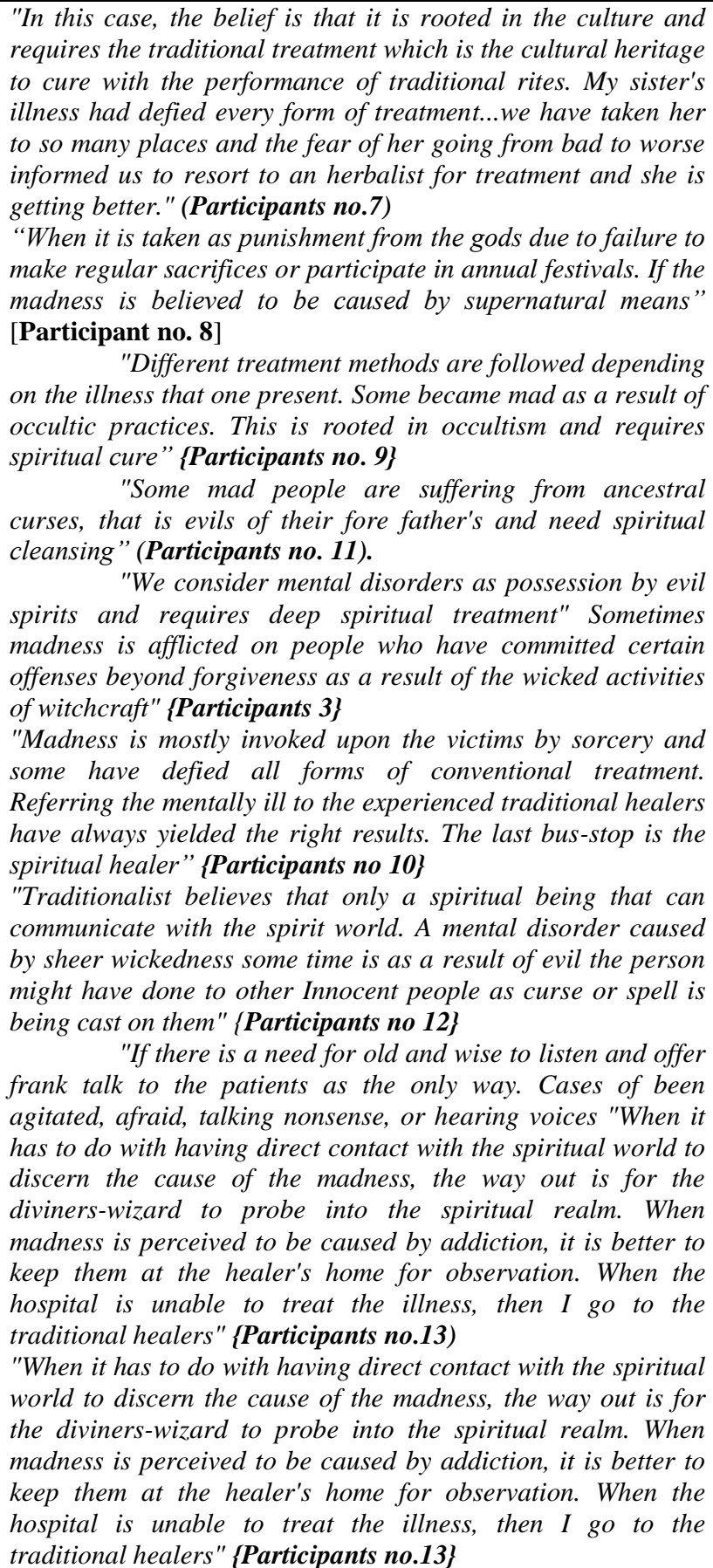 \\
\hline
\end{tabular}

\section{SUMMARY OF THE RESULTS}

The interview was conducted in the Obiaruko community of Delta State with thirteen (13) participants of the age range between 20 to above 50 years from different occupations. The sample shows that the three persons are traditional healers with a different specialty in prayers, herbs, and divination. Others are those that have taken their relatives living with mental disorders to traditional healers and from the standpoint of two (2) persons recovering from mental disorders who were oriented to time, place, and person.

Findings revealed that the pattern of traditional medicine utilization among persons living with mental disorders was mainly of a mixed form of utilization that is from orthodox to traditional or just use of traditional as the first point of contact. The data from the interview revealed that participants understood the age-long practice of the traditional medicine utilization among 
persons living with mental disorders and its curative value which they consider as highly effective. This practice according to the participants is rooted in the cultural belief and highly revered by the people of the community to provide the cure for mental disorders which include the use of herbs, supernatural power, divination, and a combination of other types of treatment depending on the mental case.

Mental disorder is believed to arise from a supernatural cause such as spirit possession, witchcraft, and breaching of taboos which are much more complex than the mainstream biomedical approach although very few persons also acknowledged drug abuse as a causative factor. The results of the study show that traditional healing from the account of the participants is a mix of several practices as well as herbalist, spiritualism, and practices based on a fallacy which is reliable with the culture of the people.

The utilization of traditional medicine is based on social, cultural, and religious attitudes which represent a combination of dynamic traditional medicine and ancestral experience. Traditional medicine utilization among persons living with mental disorders according to the participants range from flexibility, no registration is done in hospitals, confidence in the ability of the traditional healers to cure the patients, pay at convince, more effective and act faster compared to modern orthodox medicine. Traditional healers were perceived to have better communication skills in handling mental disorder patients and the link between the cultures of the people.

\section{DISCUSSION}

The findings were discussed according to the emerging themes identified that have an actual or potential relationship with the overarching objective/questions of the study.

The first research question of the study was to explore the pattern of traditional medicine utilization among persons living with mental disorders in Obiaruko. This question centers on where they went first for treatment, which forms of treatment they prefer, how long they used it, and how often they use it. The emphasis here is basically on persons recovering from mental disorders who are oriented to time, person and place, and family care givers.

The finding revealed that the majority of the persons living with mental disorders were initially taken to hospital for treatment but resort to the traditional form of treatment mainly because orthodox medicine did not meet their expectation, traditional medicine was preferred, and use was very often based on the fact that it is regarded as the main and only means of treatment when the issues of mental disorders arise as reported by most participants.
The findings of the current study are similar to findings of previous studies. For instance, Mwansisya et al., [7] noted in their study that most participants viewed orthodox treatment as an option on trial but preferred traditional treatment because supernatural forces were involved in the treatment. This is based on the cultural belief that mental disorder is supernatural in nature; they however see the health personnel as not trained on these belief syndromes to treat the condition. The findings are also consistent with the study conducted by Chilale et al., [2], who reported that the majority of the participants consulted traditional healers first, for diagnosis and finding out the person responsible for the illness. Also, Labys et al., [19] reported among the people of KwaZulu Natal that more than half of the documented participants had no dealings with proper health services in the path of their help-seeking journey; while more than two-thirds never presented at a hospital facility and only 1 in 8 used a psychiatric hospital, which also indicates traditional medicine utilization for mental disorders was among this population not assessing the hospital. However, this study is different from the results study conducted by Ibrahim et al., [6]; they noted that most participants who used psychiatric facilities had initially used the non-psychiatric treatment centers (traditional centers) as their first point of contact before visiting the formal public mental health service center.

Commonly Used Traditional Medicine among Persons Living with Mental Disorders. Exploring the commonly used traditional medicine among persons living with mental disorders was another question of the study. This question centers on the kind of traditional treatments used and the type of traditional medicines used for treatment. The emphasis here is on persons recovering from mental disorders who are oriented to time, person, and place and family caregivers and the traditional healers.

This study has brought to the fore that herbal medicines include crude plant materials such as leaves, flowers, fruits, seeds, stems, woods, roots, fresh juices, gums, mixed oils, essential oils, resins, dry powders of herbs. The herbalists used herbs for almost all types of mental disorders treatment. Specifically, the primary form of well-accepted traditional religious magical healing among every orthodox Christian is holy water and anointing oil-backed with prayers. Findings from a previous study revealed that treatment could include cleansing the patient of evil spirits through washing, steaming, induced vomiting, inhaling herbs, offering sacrifices to gods, incising out dirty blood, performing certain rituals and herbal medication [14]. Mwansisya et al., [7] are also in line with this current study as it also notes the use of spiritual healing and other traditional methods including herbal medicines in treatment. Chidarikire et al., [20] also confirm that most persons were treated by faith/ traditional healers which are also in conformity with the present study. 
Identifying factors influencing traditional medicine utilization among persons living with mental disorders was also one of the research questions answered. Highlighting reasons for preference, other reasons that contributed to the use and experience with the utilization of traditional medicine explained this theme.

The result of these findings indicates that the respondent's preference for utilization was based on the belief that it had a speedy recovery and the perception of the origin of the disorder which is rooted in the tradition and customs. Other reasons that influenced use was a cultural belief on the root cause of the disorder which ranged from the belief of supernatural cause such as spirit possession, witchcraft, and breaching of taboos which are much more complex than the mainstream biomedical approach although very few persons also acknowledged drug abuse as a causative factor. It is also believed to be the only solution for this condition. Personal experience on utilization revealed that participants' utilization of traditional medicine ranged from flexibility, no registration is done in hospitals, confidence in the ability of the traditional healers to cure the patients, pay at convince, more effective and act faster compared to modern orthodox medicine as a benefit of utilization. Traditional healers were also perceived to have better communication skills in handling mental disorder patients and the link between the cultures of the people.

This is in contrast with Sutherland [21] who noted that having less than two psychiatric admissions and a traditional healer in the family was a major reason for the utilization of traditional medicine. A study conducted by Ondicho et al., [22], shows that motives for using herbal medicine were profoundly entrenched cultural belief that herbal medicine cured certain diseases including mental disorders and maintenance of good health, this is in similarity with the present findings.

Gyasi et al., [23], noted that the use of traditional medicine was based on low-income levels, occupation (mainly trader), perception of effective treatment, and good sentimental comportment of traditional healers. This is not in conformity with the present study; the majority of the participants of the present study though not highly paid financially did not consider it as a reason for utilization because the total cost is almost equivalent to orthodox treatment. However, Stanifer et al., [24] identified major determinants for traditional medicine utilization which include credibility of traditional healers, strong cultural beliefs on the origin of the disorder, and ease in understanding line of care which conforms with the present study. However, its contracts with Luitel et al., [25], a study that identified fear of being perceived as "weak" "crazy" and being too sick to ask for help as reasons for traditional medicine utilization.
A report noted from a previous study indicated that participants connected the cause of mental disorder with witchcraft as the most significant cause which influenced the line of treatment [7]. Also, Desalegn [4] revealed that traditional healers have multiple explanations regarding the causative factors for mental disorders including supernatural, biological, and psychosocial explanations. Among these multiple explanations regarding the causes of mental illness supernatural factors were given more emphasis among traditional healers.

\section{CONCLUSION}

Persons living with mental disorders in Obiaruko Community, Delta State reported the use of traditional medicine. Commonly used traditional medicine includes herbs, prayers, and spiritual healing/cleanings. The decision to use was based on the belief in the perceived effectiveness of traditional medicine. The main cause of mental disorders identified by participants was spiritual, evil spirit, and ancestral involvement.

\section{The implication of the Study for Nursing}

Most persons in the community use traditional medicine which is deficient in scientific proof of safety and effectiveness therefore, nurses should have a practical view of mental illness based on a cultural and spiritual understanding of mental illness as well as acceptable treatment of the people in the community. Lack of proper training of nurses especially community base nurses is common in our locality hence dedicated realistic training of mental nurse specialists and application of evidence-based care mainly in community settings should be encouraged. Nursing education policy should be socio-culturally oriented in treating the mental health needs of the community.

\section{Limitations of the Study}

Accessibility of the participants was not easy. Several consultation visits were made before obtaining the required estimated sample population. It was very rigorous, and the data collection was time-consuming as the participants were not found in just one location. The scarcity of literature concerning the pattern of traditional medicine utilization in the treatment of mental disorders especially in Nigeria was also a limitation to the study. Participants recall bias and information bias was also noted during the study.

\section{RECOMMENDATIONS}

The use of traditional medicine in the treatment of mental disorders cannot be denied as it is used by a majority of persons in the community, based on this, the researchers recommend the following: Synchronized hard work by the concerned body is needed in the management, certification and utilization sustainability of traditional medicine. Federal and State Government guidelines and legislature is needed for improved and applied traditional medicine utilization in 
the treatment of mental disorders. Traditional healers have a substantial population of people living with mental disorders in the communities; therefore, more work should be conducted on the usefulness of indigenous traditional medicine approaches in the treatment of mental disorders. Nurses should actively participate in improving mental health services particularly at a community level and proper education for all stakeholders involved in the management of persons living with mental disorders for both referral and appropriate decision making.

\section{REFERENCES}

1. Monteiro, N. M. (2016). Addressing Mental Illness in Africa: Global Health Challenges and Local Opportunities. Community Psychology in Global Perspective CPGP, 1(2), 78-95.

2. Chilale, H. K., Silungwe, N. D., Gondwe, S., \& Masulani-Mwale, C. (2017). Clients and Carers Perception of Mental Illness and Factors that Influence Help-Seeking: Where they go first and why. International Journal of Social Psychiatry, 63(5), 418-425.

3. Ikwuka, U., Galbraith, M. N., Chen-Wilson, K. J., Muomah, F. C., \& Igboaka, A. (2016). Ideological vs. Instrumental Barriers to Accessing Formal Mental Health care in the Developing World: Focus on Southeastern Nigeria. Journal of Health Care for the Poor and Underserved, 27(1) 157175.

4. Desalegn, A. (2016). Conceptualization of Mental illness and Treatment practice among Traditional Healers at Gondar city. (Unpublished MA Thesis) University of Addis Ababa, Ethiopia.

5. Duru, C. B., Diwe, K. C., Uwakwe, K. A., Duru, C. A., Merenu, I. A., Iwu, A. C., Oluoha, U. R., \& Ohanle, I. (2016). "Combined Orthodox and Traditional Medicine Use among Households in Orlu, Imo State, Nigeria: Prevalence and Determinants". World Journal of Preventive Medicine, 4(1) 5-11.

6. Ibrahim, A., Hor, S., Bahar, O. S., Dwomoh, D., McKay, M. M., Esena, R. K., \& Agyepong I., A. (2016). Pathways to psychiatric care for mental disorders: a retrospective study of patients seeking mental health services at a public psychiatric facility in Ghana. International Journal of Mental Health System, 10(63), 16-341.

7. Mwansisya, T. E., \& Liu, O. Z. (2015). Perceived barriers on the utilization of mental health services among adults in Dodoma Municipality - Tanzania. Journal of Public Mental Health, 14(2):79-93.

8. Stefanovics, E. A., He, H., Cavalcanti, M., Neto, H., Ofori-Atta, H. A., Leddy, M., Ighodaro, A., \& Rosenheck, R., (2016). Witchcraft and Biopsychosocial Causes of Mental Illness Attitudes and Beliefs about Mental Illness among Health Professionals in Five Countries. The Journal of Nervous and Mental Disease, 204(3) 0022-3018.
9. Gyasi, R. M., Mensah, C. M., \& Siaw, L. P. (2014). Predictors of Traditional Medicines Utilisation in the Ghanaian Health Care Practice: Interrogating the Ashanti Situation; A journal of Community Health, 40(2): 314-325.

10. Kassis, I. T., Ghuloum, S., Mousa, H., \& Bener, A. (2014). Treatment noncompliance of psychiatric patients; are patients satisfied with their psychiatrist? British Journal of Medicine and Medical Research, 4(2) 785-796.

11. Creswell, J. W. (2014) Research design: qualitative, quantitative, and mixed methods approach - 4th ed.

12. Boateng, M. A., Danso-Appiah, A., Turkson, B. K., \& Tersbøl, B. P. (2016). Integrating biomedical and herbal medicine in Ghana experiences from the Kumasi South Hospital: a qualitative study. BMC Complementary and Alternative Medicine, 16:189.

13. Dibie, G. A. (2017). Obiaruku Women and Economic Development. International Journal of Engineering and Information Systems, 1(8), 124134.

14. Ngobe, A. J. (2015). Swati traditional healers' conceptualization of causes and treatment of mental illness. (Unpublished MA thesis), University of Limpopo, Polokwane, South Africa.

15. Fusch, P. I., \& Ness, L. R. (2015). Are We There Yet? Data Saturation in Qualitative Research. The Qualitative Report, 20(9), 1408-1416.

16. Yin, R. K. (2014). Case study research: Design and methods (5th ed.). Thousand Oaks: Sage.

17. Kallio, H., Pietila, A., Johnson, M., \& Kangasniemi, M. (2016). Systematic methodological review: developing a framework for a qualitative semi-structured interview guide: $A$ Journal of Advanced Nursing, 72(12).

18. Ghafouri, R., \& Ofoghi, S. (2016). Trustworthy and Rigor in Qualitative Research. International Journal of Advanced Biotechnology and Research, 7(4):1914-192.

19. Labys, I., Susser, E., \& Burns, J. K. (2016) Psychosis and help-seeking behavior in rural KwaZulu Natal: unearthing local insights Charlotte A. International Journal of Mental Health System, 10(57).

20. Chidarikire S., Cross, M., Skinner, I., \& Cleary, M. (2018). Treatments for people living with schizophrenia in Sub-Saharan Africa: an adapted realist review. International Nursing Review, 65(1), $78-92$.

21. Sutherland, T. (2015). A retrospective review of lifetime prevalence of traditional healer consultation by an outpatient sample of Xhosa schizophrenia sufferers (Unpublished MA thesis), University of Witwatersrand, Johannesburg, South Africa.

22. Ondicho, J., Ochora, J., Matu, E., \& Mutai, J. (2015). Factors Associated with Use of Herbal Medicine Among Patients in Herbal Clinics 
InGucha District, Kenya: The JKUAT Scientific Conference Basic and Applied Sciences. 1(2015), 1-17.

23. Gyasi, R. M. (2014). Analysis of Factors Influencing Traditional Medicines Utilisation in Ghana: Evidence from Kumasi Metropolis and Sekyere South: A Journal of Ethnopharmacology, 161(1), 138-146.

24. Stanifer, J. W., Patel, U. D., Karia, F., Thielman, N., Maro, V., \& Shimbi, D. (2015). The
Determinants of Traditional Medicine Use in Northern Tanzania: A Mixed-Methods Study. PLoS ONE. 10(4).

25. Luitel N. P., Jordans M. J. D., Kohrt, B. A., Rathod, S. D. \& Komproe, I. H. (2017). Treatment gap and barriers for mental health care: A crosssectional community survey in Nepal. PLoS ONE. 12(8): 